\title{
Is pregnancy a risk factor in the causation of rheumatoid arthritis?
}

\author{
ALAN J SILMAN \\ From the Department of Clinical Epidemiology, The London Hospital Medical College, London
}

It is well established that the physiological changes in pregnancy can affect the course of rheumatoid arthritis (RA). Thus pregnancy is associated witn remission of the disease in the last trimester, which frequently relapses after delivery. ${ }^{1}$ This may be explained by the large rise in female sex hormone concentration and the subsequent fall postnatally. The disease suppression has also been related to the concentration of pregnancy serum $\alpha_{2}$ glycoprotein (PAG) ${ }^{2}$ though PAG levels in their turn are related to female sex hormones. ${ }^{3}$ The possibility that such hormones affect RA disease activity is supported by the observation that the latter fluctuates during different stages of the menstrual cycle. ${ }^{4}$ These and other studies ${ }^{5}$ have prompted increased interest as to whether female sex hormones also have a role in the causation of RA. The most prominent hypothesis is that exogenous female sex hormones, specifically the oral contraceptive pill, protect against the development of RA.

\section{ORAL CONTRACEPTIVE (OC) USE AND}

RHEUMATOID ARTHRITIS

The first report suggesting a protective effect of $O C$ use resulted serendipitally from a longitudinal study of 50000 women in general practice aimed at detecting the general health effects from long term OC use. ${ }^{6}{ }^{7}$ Women still taking OCs at the end of the 10 year follow up period ('current users') had half the incidence of RA of women who had never used OCs. Women initially using OCs but who stopped their usage during the follow up had an intermediate risk, thereby suggesting a dose-response effect. The magnitude of the reduction in the current users led the authors to estimate that $O C$ use was associated with the not inconsiderable reduction in RA

Accepted for publication 5 June 1986.

Correspondence to Dr Alan J Silman, Department of Clinical Epidemiology, The London Hospital Medical College, London E1 2AD. incidence of 0.3 per 1000 per year. The difference observed in that study persisted after adjustment for age and parity, though there were a number of potential artefactual explanations. First, women stopped using OCs as a result of early RA symptoms, thus giving an apparent benefit to OC users at the end of the study. Secondly, the diagnosis of RA was made from general practice records that might not have been accurate. Nevertheless, the difference was so large that a further study of OC use and RA became an important topic for rheumatoid arthritis epidemiology. 89

Four further studies, all using a case-control design, have been published recently, one supporting a protective effect, ${ }^{10}$ two finding no benefit ${ }^{11} 12$ (the second being an extended and more rigorous version of the first), and one with equivocal results, ${ }^{13}$ perhaps due to small numbers. The methodological aspects of these studies have been discussed in detail in an attempt to explain the divergent results, ${ }^{14-16}$ and lengthy epidemiological discussion has failed to reconcile the differences. The US National Institute of Health in 1984 was sufficiently impressed by the potential importance of the question that it expressed a willingness to sponsor 'the definitive' case-control study. ${ }^{17}$ Intriguingly, a further study published this year by the Dutch group $^{10}$ has shown a similar reduction in RA in women taking postmenopausal hormones. ${ }^{18}$

It is, however, difficult to explain both the divergent results and the failure to find a doseresponse effect (as measured by duration of OC use) even in the most positive study. ${ }^{10}$ Further, any explanation would need to overcome the difficulty of $\mathrm{OC}$ use representing exposure to a large range of hormone formulations. Since their introduction there have been considerable changes both quantitatively and qualitatively in OC formulation. Even current preparations vary in progesterone content between 0.03 and $4.0 \mathrm{mg}$, with an oestrogen content 
varying between 20 and $50 \mu \mathrm{g} .{ }^{19}$ It is perhaps unlikely that all formulations would have the same effect in preventing RA, and this would perhaps partly explain the failure to find a dose-response effect.

It seems unlikely that $\mathrm{OC}$ use could be protective for some populations but not for others, and, arguably, the absence of a plausible biological hypothesis decreases the likelihood that the inverse association represents causation. ${ }^{20}$ Thus it is appropriate to consider other explanations for those studies that have found a link. One possibility is that OC use might be a marker for another variable that is the protective factor against RA, such a confounder being pregnancy avoidance. Women who use $\mathrm{OC}$ are likely to have a later first pregnancy and lower gravidity than non-OC users as was found, for example, in a study of women doctors, ${ }^{21}$ though the non-OC users in that study were older. If pregnancy or repeated pregnancies increase the risk of RA development it is of relevance to examine the available epidemiological data pertinent to this question and these are discussed below.

PREGNANCY AND RHEUMATOID ARTHRITIS

Women are obviously uniquely exposed to pregnancy as a 'risk factor', which is of interest given that one of the consistent aspects of the epidemiology of rheumatoid arthritis (RA) is the two- to threefold female predominance in most series. ${ }^{8}$ This excess is apparent in all populations studied, both Caucasian and non-Caucasian. It was, for example, recently demonstrated in an island off the east coast of China that had reported one of the lowest recorded occurrences of RA. ${ }^{22}$ The increased incidence of RA in women declines postmenopausally, ${ }^{23}$ and by the age of 70 the incidence in the two sexes is similar. ${ }^{24}$ Others have found no such menopausal decline, with females retaining their increased risk into the eighth decade. ${ }^{25} \mathrm{~A}$ female excess is not, however, unique to RA but is rather a phenomenon seen frequently in other autoimmune diseases. In this regard the demonstration that women with 'poor reproductive histories' are more likely to develop autoimmune thyroid disease is of interest, ${ }^{26}$ especially given the link between the latter and RA in families. ${ }^{27}$

The US Health Examination Survey 20 years ago showed that there was a graded risk of RA with marital status. ${ }^{28}$ Thus single women were at the lowest risk, married women at the highest, and women with failed marriage at an intermediate risk (Fig. 1). Such a hierarchy is reasonably associated with increased exposure to pregnancy, though in part could be explained by age differences between

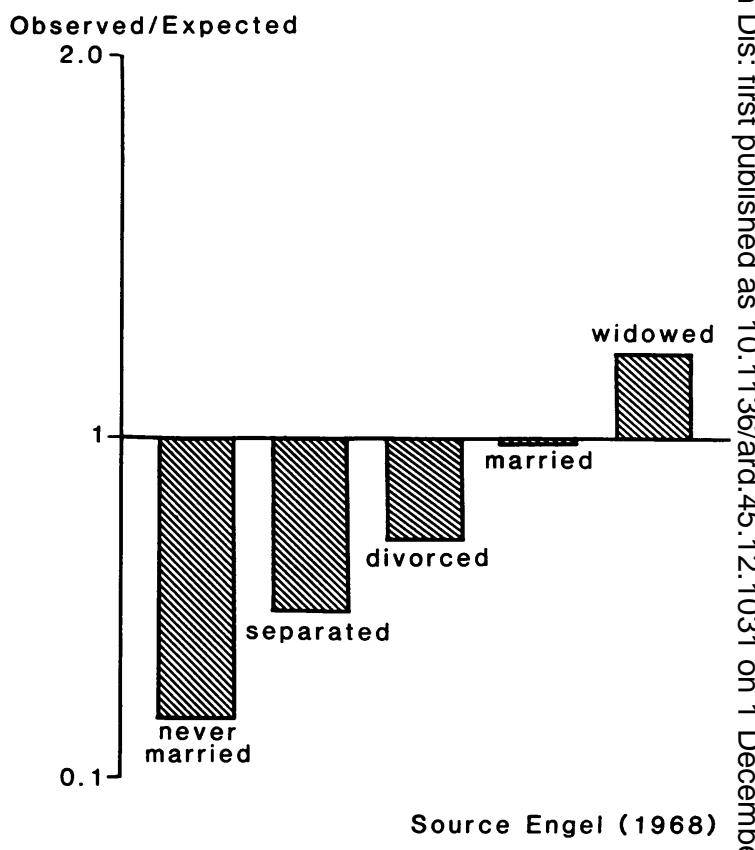

Fig. 1 Rheumatoid arthritis: prevalence by marital status. \&

the marital groups. The same survey showed tha the age adjusted prevalence of RA was lowest in nulliparous women and highest in those with more than four children ${ }^{28}$ (Fig. 2). Other studies, however, have found no effect of marital status. ${ }^{232930} \mathrm{~A}$ study by Kay and Bach also showed a lower fertility $\overrightarrow{\vec{O}}$ rate in women with RA than in age matched controls. ${ }^{30}$ This observation was partly ascribed to the effect of the disease, but reduced fertility was seen even in the subgroup with postmenopausal disease onset. There were differences, however, between seropositive and seronegative women (as classified by the serological techniques available at that time), the former having a higher fertility before disease onset. This group also had a higher

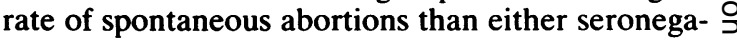
tive or control women. Thus pregnancy experience $D$ may be a risk factor in the aetiology of seropositive disease, with failed pregnancy a more potent risk $N$ factor. The latter would be consistent with the study on autoimmune thyroid disease mentioned above. O

Epidemiological data collected for other purposes $\mathrm{c}$ can be examined for their consistency in regard to the pregnancy hypothesis. There are differences in 0 the association of HLA, and in particular the class II $\mathbb{D}$ antigen DR4, and RA between men and women. A $\stackrel{?}{+}$ study of 440 RA patients showed that with increas- $T$ ing age of RA onset there was a linearly decreasing 


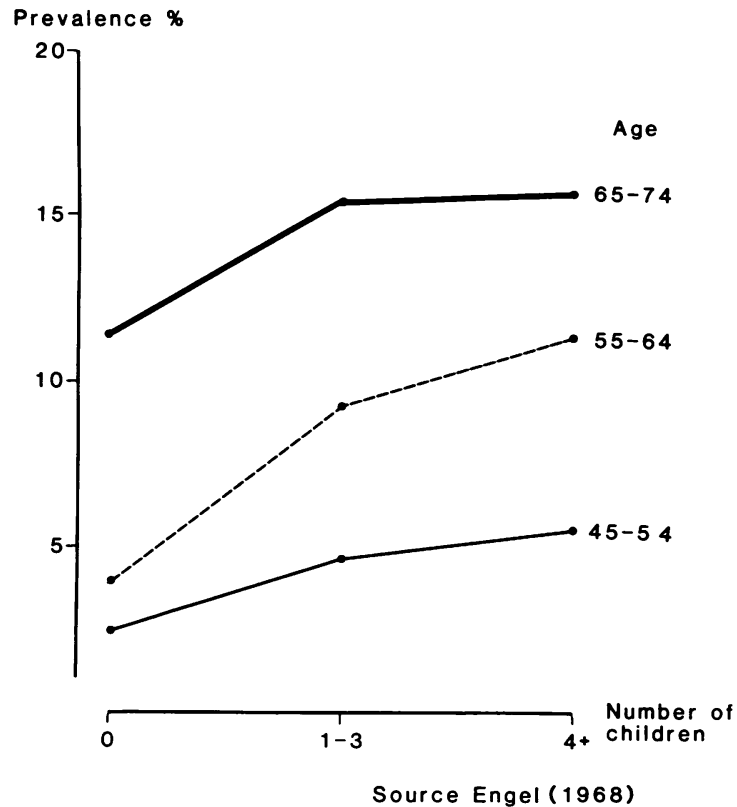

Fig. 2 Age specific prevalence rates of rheumatoid arthritis in adult women by number of children.

likelihood of a women being DR4 positive. ${ }^{31}$ If DR4 is a marker for a genetic influence on disease aetiology then it is required to a greater extent in younger women. Conversely, in older women 'environmental' factors become progressively more important. Men did not show this phenomenon, suggesting that such putative environmental factor(s) change is restricted to women. The linear trend makes this factor unlikely to be the simple onset of the menopause as the progressive decline with age was observed premenopausally. The trend could be associated with increasing pregnancy experience as women age. It would be interesting to compare the HLA-DR4 status in parous and multiparous RA patients matched for age.

There is other indirect evidence possibly linking pregnancy with RA. Data from the Mayo Clinic showed a fairly convincing decline in RA incidence in Olmstead county since 1960 in women but not in men, ${ }^{25}$ though the difference in trends was not statistically significant. ${ }^{12}$ Although the decline was initially ascribed to trends in $\mathrm{OC}$ use, a subsequent case-control study of $O C$ use in those same women showed no such association. ${ }^{11}$ An alternative explanation for the decline in these women is a reduced age adjusted pregnancy experience in the more recent cohorts. Such trends have been observed in England and Wales, with a shift towards older age at pregnancy and a reduction in total fertility. ${ }^{32}$ Contemporaneously there has been a trend towards a lower rate of seropositive RA in clinic attenders ${ }^{33}$; which would be consistent with the observation above.

\section{Conclusions}

There are epidemiological data supporting the hypothesis that nulliparity is protective against seropositive RA and that increasing pregnancy experience, possibly restricted to pregnancies with an adverse output, might increase the risk. It is difficult to sustain such a hypothesis on epidemiological evidence alone without a coherent biological mechanism. Thus the link between RA and pregnancy may be immunologically mediated by fetal stimulation of the maternal immune system, which might occur progressively with repeated pregnancies and thus result in the production of autoantibodies. In pregnancies which have an adverse outcome, for example spontaneous abortion, this might suggest greater fetomaternal incompatibility. There is obviously large scope for retrospective studies of reproductive history in women with RA and prospective clinical and serological studies of women with poor reproductive histories.

\section{References}

1 Persellin $\mathrm{R} \mathrm{H}$. The effect of pregnancy on rheumatoid arthritis. Bull Rheum Dis 1977; 27: 9226.

2 Ungar A, Kay A, Griffin A J, Panayi G S. Disease activity in rheumatoid arthritis during pregnancy. $\mathrm{Br}$ Med $J$ 1983; 286: $750-2$.

3 Thomson A W, Horne C $\mathrm{H} \mathrm{W}$. Biological and clinical significance of pregnancy associated alpha-2 glycoprotein (2PAG). Invest Cell Pathol 1980; 3: 295-302.

4 Rudge S R, Kowanko I C, Drury P L. Menstrual cyclicity of finger joint size and grip strength in patients with rheumatoid arthritis. Ann Rheum Dis 1983; 42: 425-30.

5 Lahita R G. Sex steroids and the rheumatic diseases. Arthritis Rheum 1985; 28: 121-6.

6 Wingrave S, Kay C R. Reduction in incidence of rheumatoid arthritis associated with oral contraceptives. Lancet 1978; i: 569-71.

7 Royal College of General Practitioners. Oral contraceptives and health: interim report. London: Pitman Medical, 1974.

8 Hochberg M C. Adult and juvenile rheumatoid arthritis: current epidemiologic concepts. Epidemiol Rev 1981; 3: 27-44.

9 Allander E, Bjelle A. Developments in epidemiological studies on rheumatoid arthritis. Scand J Rheumatol 1981; 10: 257-61.

10 Vandenbroucke J P, Valkenburg H A. Boersma J W, et al. Oral contraceptives and rheumatoid arthritis: further evidence for a protective effect. Lancet 1982; ii: 839-42.

11 Linos A, Worthington J N, O'Fallon W M. Kurland L T. Casecontrol study of rheumatoid arthritis and prior use of oral contraceptives. Lancet 1983; i: 1299-300.

12 del Junco D J, Annegers J F, Luthra H S, Coulam C B, Kurland $\mathrm{L} \mathrm{T}$. Do oral contraceptives prevent rheumatoid arthritis? JAMA 1985; 254: 1938-41.

13 Allebeck P, Ahlbom A, Ljungstrom K, Allander E. Do oral 


\section{Silman}

contraceptives reduce the incidence of rheumatoid arthritis? Scand J Rheumatol 1984: 13: 140-6.

14 Kay C R. Wingrave S J. Oral contraceptives and rheumatoid arthritis. Lancet 1983; i: 1437.

15 Vandenbroucke J P. Oral contraceptives and rheumatoid arthritis. Lancet 1983; ii: 200-1.

16 Esdaile J, Horwitz R. Resolving contradictory results in epidemiologic studies of oral contraceptives and rheumatoid arthritis. Clin Res 1984; 32: 462A.

17 Department of Health and Human Services. Case-control study of the risk of rheumatoid arthritis in relation to oral contraceptive use. Bethesda: NIH, 1984. (Request for proposals No NICHDCE 84-5.)

18 Vandenbroucke J P. Witteman J C M. Valkenburg H A, et al. Non-contraceptive hormones and rheumatoid arthritis in perimenopausal and post-menopausal women. JAMA 1986; 255: $1299-303$.

19 MIMS. Monthly index of medical specialties. London: Medical Publications Ltd. November 1985.

20 Hill A B. A short textbook of medical statistics. London: Hodder and Stoughton. 1977.

21 Alberman E, Pharoah P. Chamberlain G, Roman E, Evans $\mathrm{S} \mathrm{J} \mathrm{W}$. Outcome of pregnancies following the use of oral contraceptives. Int J Epidemiol 1980; 9: 207-13.

22 Beasley R P, Bennett P H. Lin C C. Low prevalence of rheumatoid arthritis in Chinese. Prevalence survey in a rural community. J Rheumatol 1983; 10 (suppl 10): 11-5.

23 Lawrence J S. Rheumatism in populations. London: Heinemann, 1977.

24 Wood P H N. Age and the rheumatic diseases. In: Bennett P H. Wood P H N, eds. Population studies of the rheumatic diseases.
Amsterdam: Excerpta Medica. 1968. (Proceedings of the Third International Symposium on Rheumatic Diseases.)

25 Linos A. Worthington J W. O'Fallon W M. Kurland L T. The epidemiology of rheumatoid arthritis in Rochester. Minnesota: a study of incidence. prevalence and mortality. Am J Epidemiol 1980; iii: 87-98.

26 Beral V. Roman E, Colwell L. Poor reproductive outcome in insulin-dependent diabetic women associated with later development of other endocrine disorders in the mothers. Lancet 1984: i: 47.

27 Grennan D M, Dyer P A. Clague R. et al. Family studies in rheumatoid arthritis: the importance of HLA-DR4 and of genes for auto-immune thyroid disease. J Rheumatol 1983: 10: 584-9.

28 Engel A. Rheumatoid arthritis in US adults 1960-62. In: Bennett P H. Wood P H N, eds. Population studies of the rheumatic diseases. Amsterdam: Excerpta Medica. 1968. (Proceedings of the Third International Symposium on Rheumatic Diseases.)

29 Hellgren L. Marital status in RA. Acta Rheumatol Scand 1969; 15: 271 .

30 Kay A. Bach F. Subfertility before and after the development of rheumatoid arthritis in women. Ann Rheum Dis 1965; 24: $169-73$.

31 Jaraquemada D, Ollier W. Awad J, et al. HLA and rheumatoid arthritis: a combined analysis of 440 British patients. Ann Rheum Dis 1986; 45: 627-36.

32 Office of Population Censuses and Surveys. Birth statistics 1983 England and Wales. London: HMSO, 1985.

33 Silman A. Davies P. Currey H L F. Evans S J W. Is rheumatoid arthritis becoming less severe. J Chronic Dis 1983: 36: 891-4 